\title{
Considerations in Orthodontic Bracket Adhesion to Hypomineralized Enamel
}

\author{
Shabtai Sapir \\ Department of Pediatric Dentistry, Hebrew University- Hadassah Faculty of Dental \\ Medicine, Jerusalem, \\ Israel
}

\section{Introduction}

Developmental defects of enamel (DDE) are frequently observed. In both pediatric and orthodontic dental practices. DDE consist mainly of hypoplasia, diffuse and demarcated opacities. ${ }^{1}$ Often, a combination of enamel defects may be recognized in the same child (Fig. 1). Weerheijm et al. defined the term Molar Incisor Hypomineralization (MIH) to describe a more specific pattern of DDE: hypomineralization of systemic origin of one to four permanent first molars frequently associated with affected incisors (Fig. 2). ${ }^{2}$

Clinically, MIH can be seen as an abnormality in the translucency of the enamel. Some lesions have significant subsurface porosity, leading to posteruptive breakdown of the surface.

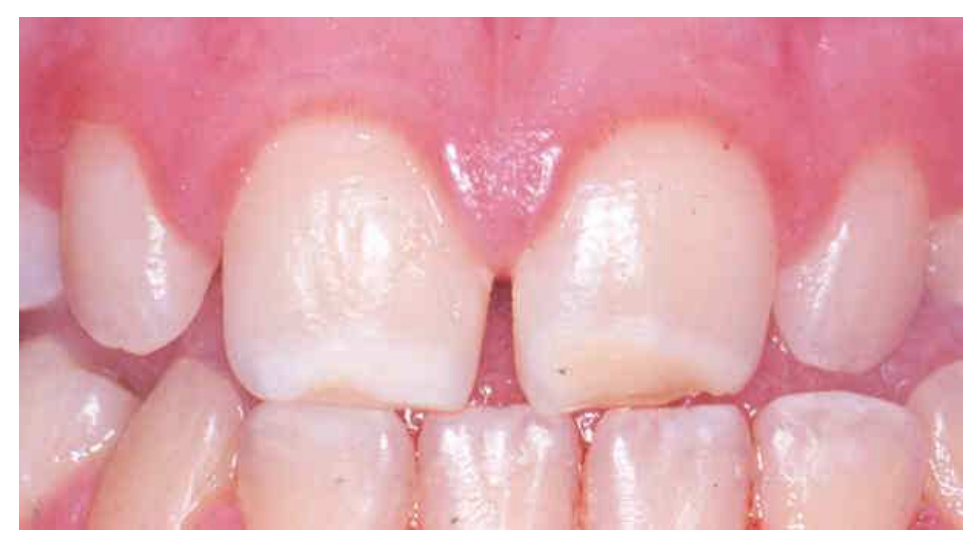

Fig. 1. Intraoral view of an 11-year-old girl at the initial examination, with hypoplasia of the incisal edges of her upper central incisors.

The opacities are usually limited to the incisal or cuspal one third of the crown, more commonly on the buccal surfaces. The enamel surface is often smooth and well mineralized, following post-eruptive maturation. The subsurface enamel is soft and porous. ${ }^{3}$ The color of the opacities may reflect differences in hardness, porosity and mineral content. Yellow or yellow-brown demarcated opacities have lower hardness values and greater porosity. Mostly they cross the entire bulk of enamel, as opposed to white and white-creamy defects, 
which are usually limited to the inner enamel, closer to the Dentino-Enamel Junction (DEJ).3,4 Patients may complain of one or more of the following: poor esthetics, thermal and mechanical sensitivity, attrition, secondary caries, tooth discoloration, malocclusion and periodontal problems. ${ }^{2,5}$

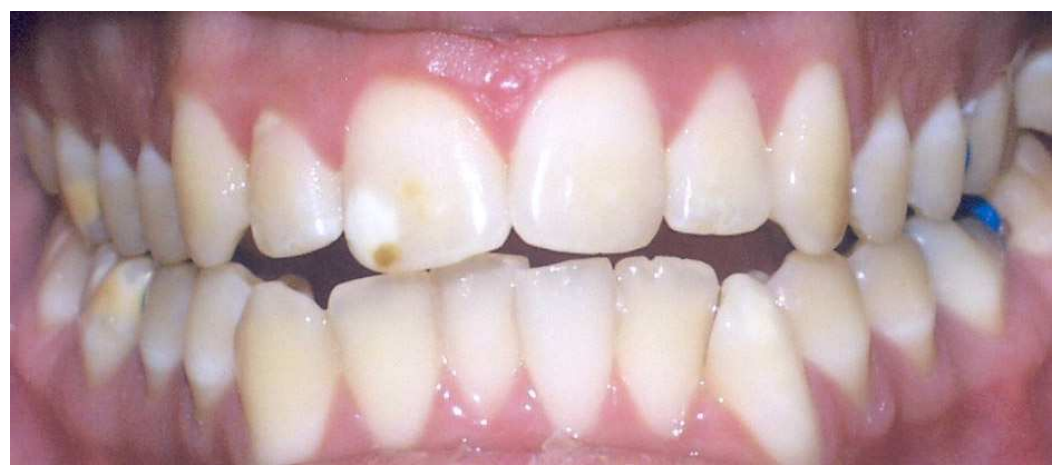

Fig. 2. Intraoral view of a 17-year old adolescent presented with $\mathrm{MIH}$ with low-moderate severity

Early diagnosis of DDE is important for appropriate treatment planning and for prevention of future complications. An accurate diagnosis may improve the clinician's dental care in many aspects: caries risk assessment, aesthetics, improved adhesion, retention, durability and debonding of orthodontic bands and brackets. Furthermore, financial considerations, behavioral management, and medico-legal issues can be affected by early identification of DDE. $6-11$

The purpose of this article is to discuss those pre-treatment and treatment considerations that may affect: a) The management of the young patient diagnosed with demarcated opacities; and b) Choice of adhesive material and technique used for bonding and debonding of orthodontic brackets in a patient affected by demarcated opacities.

The management of the young patient diagnosed with demarcated opacities may be divided into two parts:

1. Preliminary dental consultation and treatment prior to adhesion of fixed orthodontic appliance

2. Appliance adhesion, materials and debonding- technique.

\section{Preliminary dental treatment prior to adhesion of fixed orthodontic appliance}

May be divided into:

a. Early diagnosis and risk assessment.

b. Informed consent from the guardians/ patient

c. Post-eruption breakdown, prevention of dental caries, enhancing remineralization and desensitization.

d. Considering long-term prognosis of affected teeth and, if necessary, deciding upon extractions or restoration.

\section{Early diagnosis and risk assessment}

Children with demarcated opacities should be diagnosed early in their consultation visits. Documentation both written and photographic should be recorded in the patient's file. The 
patient's chief complaint, in conjunction with the biochemical and morpho-histological characteristics of the defects, may affect the prognosis and management.3,12,13 The extent of the problem depends upon the number of the teeth involved and the severity of the defects (depth, size, color and enamel break-down). In addition, information of the patient's caries risk assessment, diet, oral hygiene and compliance can provide the clinician with an assessment of the risk for possible future complications such as: post-eruption breakdown of enamel around brackets and bands, objectionable color changes, higher risk of demineralization and caries, and the possible need to restore those lesions prior to the orthodontic treatment or shortly there after.5,14 The orthodontist may prefer to refer the patient to other specialists for risk assessment, preventive plan and dental treatment. Nevertheless the clinician is advised to follow carefully the suggested treatment plan, to maintain the patient's compliance and document it routinely as the orthodontic treatment progresses. Some cases should be denied treatment based on enhanced risk for further deterioration of tooth substance.

\section{Informed consent from the guardians/ patient}

The informed consent prior to utilizing the orthodontic treatment should specify the problems that may arise following bonding and debonding of orthodontic appliances. This may include: post-eruption breakdown of enamel around brackets and bands, objectionable color changes, higher risk for demineralization and caries, and the possible need to restore those lesions prior to the orthodontic treatment or shortly after it is commenced or finished. An essential part of the informed consent is compliance with the preventive program and the accomplishment of the necessary dental treatment prior, during and sometimes following the orthodontic treatment.

\section{Post-eruption breakdown, prevention of dental caries and, enhancing remineralization, and desensitization.}

The recommended preventive treatment ought to be given according to the individual patient's symptoms and risk assessment. The cariogenicity and erosivity of the child's diet should be assessed and appropriate recommendations for dietary modification provided. Oral hygiene instructions may include the use of the appropriate tooth brush and desensitizing toothpaste if necessary. ${ }^{14}$

Weekly topical fluoride gel or varnish applications, and daily sodium fluoride rinses may improve resistance to demineralization, decrease tooth sensitivity and enhance enamel remineralization and post eruptive maturation. ${ }^{15}$ Daily application of casein phosphorpeptide-amorphous calcium phosphate (CPP-ACP), reportedly enhances remineralization 16,17 Anecdotal reports describe surface hardening and reduced tooth sensitivity and esthetic improvement of opacities and demineralized enamel.5,18

Monthly follow-up visits should be scheduled for enamel surface integrity inspection and for the application of $5 \%$ sodium fluoride varnish such as Duraphat (2.26\%F-ColgatePalmolive) or the new white varnish Vanish (2.26\%F-OMNII-Oral Pharmaceuticals).

\section{Dental treatment considering long term prognosis of affected teeth and if necessary decide upon extractions.}

A multidisciplinary approach that may involve other specialists such as a pediatric dentist, prosthodontics and a dental hygienist can contribute in offering a preventive program, and lead to decision on the type of restorations that may be offered prior to the orthodontic treatment. ${ }^{19,20}$ 
When a Permanent First Molar is severely hypomineralized, early orthodontic and prosthetic assessment is essential. Evaluation of the patient's and/or guardian's preferences, behavior management, financial issues, compliance, tooth vitality, restorability, dental age, skeletal relationship and growth, buccal segment crowding, occlusal relationships, presence of wisdom teeth, and the condition of other teeth, may influence the long term prognosis and dictate immediate restoration or extraction. 5,21-23

When the molars are moderately or severely involved stainless steel crowns (SSC) may be considered. They prevent further tooth deterioration, and sensitivity, establish correct inerproximal contacts and occlusal relationship, are not as technique-sensitive or costly as cast restorations, and require little time to insert. Following orthodontic treatment, once the gingival contour is stabilized, cast adhesive crowns may be adjusted according to the final position of the tooth to provide ideal aesthetics. $5,20,22$

\section{Appliance adhesion and debonding technique and materials}

To date no research on bonding of orthodontic appliances to hypomineralized teeth has been published, however, recent research articles on different adhesives and performance of bonding materials in adhesion to normal and hypomineralized enamel may improve our knowledge of adhesion to teeth affected with $\mathrm{MIH}$ and help suggest educated recommendations.

The aspects that should be discussed include:

1. Type of adhesive etching, priming and bonding.

2. Enamel prophylaxis and fluoride exposure (prior to bonding).

3. Anti-cariogenic effect of adhesives and fluoride release.

4. Debonding and residual adhesive removal.

5. Modifications necessary for adhesion to hypomineralized enamel.

\section{Type of adhesive etching, priming and bonding}

The type of adhesive and the enamel conditioning chosen may determine the clinical outcome of adhesion to hypomineralized enamel. The adhesive materials used for cementing and bonding of bands and brackets commonly used in modern orthodontic practice are based on: GIC (Glass Ionomer Cement), RMGIC ( Resin Modified GIC), Polyacid modified Glass ionomer (compomer), and Resin composite.

Enamel may be conditioned in different ways: $10 \%$ Polyacrylic acid, a non-rinse conditioner, and conventional two-stage etching and priming process with 35\%-37\% phosphoric acid. Manufactures have simplified some adhesive systems by combining the hydrophilic primer and the adhesive, and recently introduced products with primers modified with various acidic components. The following are Non-rinse conditioners: (NRC, Dentsply De Trey), Adper Prompt L-Pop Self Etch Adhesive, 3M, St. Paul, Minn (Adper PLP), Clearfil SE Bond /Protect Bond, (Kuraray Medical Inc, Tokyo, Japan), and Transbond Plus Self Etching Primer (TSEP, $3 \mathrm{M}$ Unitek). The $\mathrm{pH}$ of these acidified or self-etching primers has been reduced to the extent that they can effectively etch enamel to the same degree as phosphoric acid.24-28

\section{Anti-cariogenic effect of adhesives and fluoride release}

The fluoride released from adhesives based on RMGIC (Fuji Ortho LC (GC), is significantly greater than from resin based adhesives such as Transbond XT (3M Unitek ). ${ }^{24}$ However, the values were similar between fluoride release of RMGIC (Fuji Ortho LC (GC) and resin adhesives that were enhanced with external application of fluoride. ${ }^{29}$ Similar results were seen in prevention of demineralization. ${ }^{30-32}$ Resin composite based adhesives with internal release 
capability of fluoride were found to slow down demineralization when compared to regular resin composite adhesive even though less effectively than the RMGIC based adhesives. ${ }^{32}$

At present there is no research to support the claims by Transbond Plus Self Etching Primer and Clearfil Protect Bond manufacturers that they are capable of releasing fluoride in substantial levels to diminish enamel demineralization. The clinical efficiency of Clearfil Protect Bond, which is claimed to possess an antibacterial effect attributed to the 12MethacryloyloxyDodecyl Pyridinum Bromide (MDPB) molecule, is yet unproved.

\section{Enamel prophylaxis and fluoride exposure (prior to bonding)}

The hypomineralized tooth is usually characterized by well mineralized surface enamel.3,4 The clinician should attempt to preserve it as intact as possible. Most adhesive manufactures recommend cleaning teeth of organic enamel pellicle and plaque by using prophylaxis paste or pumice prior to adhesion of orthodontic brackets. A rubber cup is preferred over a bristle brush since it causes less enamel loss. ${ }^{33}$ The abrasive paste used is less detrimental than the type of brush. ${ }^{34}$ Pumice prophylaxis prior to conventional acid etching and adhesion with composite resin bonding agent or with GIC/RMGIC does not seem to reduce bond failure rates. ${ }^{35,36}$ However, omitting prophylaxis when a self etching primer is used may increase the amount of clinical bond failures. ${ }^{37}$

Prophylaxis pastes containing up to $13,500 \mathrm{ppmF}$ were not found to adversely affect the adhesion of orthodontic brackets to normal enamel. ${ }^{38}$

The application of $\mathrm{NaF}$ fluoride varnish has not adversely affected the adhesion of orthodontic brackets to normal enamel, either when the enamel was conditioned with self etching primer or etched with $37-35 \%$ phosphoric acid. ${ }^{39,40}$ Nevertheless, application of APF fluoride gel prior to orthodontic brackets adhesion resulted in lower adhesion. ${ }^{41}$

\section{Debonding and residual adhesive removal.}

The debonding of brackets and bands might cause further break-down of enamel. The amount of enamel loss depends on the bracket material, bonding and adhesive methods used and on the method of debonding. Ceramic brackets reportedly cause more enamel loss and fracture at debonding than metal brackets, ${ }^{42,43}$ Metal bracket removal after adhesion with a resin composite resulted in 7.4 micron on average loss of enamel surface. ${ }^{44}$ An in vitro study has not found significant differences in enamel loss between teeth with white spot lesions and teeth without white spot lesions, following orthodontic bracket debonding and polishing with low-speed finishing burs or disks. ${ }^{45}$ However, there are no studies that examined enamel loss in more severe cases of enamel hypomineralization.

The adhesives based on RMGIC have excellent results in ease of removal, lower Adhesive Remnant Index (ARI) scores, and a lower risk of damaging enamel surface.27,28,30 Self etching primer systems have also been reported to produce good ARI scores as compared to traditional acid-etch technique. ${ }^{46-48}$

The removal of the residual adhesive can be accomplished via debonding pliers, ultrasonic scaler, high-speed tungsten carbide bur or by low-speed tungsten carbide bur Debonding pliers cause the least enamel loss, however more residual adhesive remained. ${ }^{48}$ The least enamel loss was reported to occur with self-etching primer and after enamel clean-up with a slow-speed tungsten carbide bur with water. ${ }^{48}$

\section{Modifications necessary for adhesion to hypomineralized enamel}

The ideal adhesive for orthodontic purpose should provide long retention, anti-cariogenic features, biocompatibility, simplicity, aesthetics, reasonable price, and easy debonding along 
with preservation of enamel integrity. Some of these demands are crucial for the clinician bonding a fixed appliance to hypomineralized enamel. Theoretically, self-etching primer adhesive system (SEPAS), and RMGIC based adhesives may be more advantageous when orthodontic adhesion to hypomineralized enamel is required. The use of conventional etching and priming is discouraged since phosphoric acid, may cause more enamel loss than self etching primers. 47,48 This might reduce adhesion to hypomineralized enamel, because of inadequate micro-tag formation, consequential to the formation of little intercrystal porosity..$^{19}$ Other possible effects of severe enamel loss are: increased micro leakage around brackets with potential connection between enamel surface and the subsurface opacities, which might produce either an objectionable color change following extrinsic staining or a higher risk for demineralization and postoperative sensitivity.

Moreover, All-etch single-bottle adhesive - Single Bond, (3M ESPE, St. Paul, Minn, USA), and a SEPAS-Clearfil SE Bond, did not differ significantly in their ability to bond to hypomineralized enamel. ${ }^{19}$ Subsequently, no apparent incentive to choose phosphoric acid over SEPAS possibly will remain.

New self-etching adhesives (TSEP, Clearfil Protect Bond) may offer an alternative that meets the challenge of adhesion to hypomineralized enamel better:

1. They cause less enamel loss. 47,48

2. They are simpler to use.

3. Rinsing is omitted. Therefore wet conditions that inhibit resin infiltration are prevented. The larger interprismatic spaces in hypomineralized enamel may promote moisture retention and structural weakness and crack propagation. ${ }^{19}$ Also the proven efficacy of SEPBS in bonding better than conventional two-stage etching and priming systems in wet conditions may be beneficial in cases of hypomineralized enamel. ${ }^{49-51}$

4. Some SEPBS (Clearfil SE Bond/ Protect bond, to bond both, micromechanically and chemically to hydroxyapatite due to incorporation of the 10-Methacryloxydecyl Dihydrogen Phosphate (MDP) molecule, whereas conventional bonding relies primarily on micromechanical retention. The latter may be limited because of minimal intercrystal porosity, and microtag formation after etching hypomineralized enamel. ${ }^{19}$

5. Some SEPBS Clearfil SE Bond/ Protect bond, and Transbond Plus Self Etching Primer have fluoride- releasing qualities and the Protect bond also has an antibacterial component; Even though, presently no research has been published to support its clinical efficiency, this may still be an encouraging development.

6. The improved adhesion and diminished microleakage of some self-etching primers Clearfil SE Bond/ Protect bond, in adhesion to normal enamel, ${ }^{52-55}$ might also be seen in adhesion to hypomineralized enamel, since the demineralization and resin penetration occur concurrently, therefore the etching depth and the resin penetration depth might be similar. 19

7. SEPBS cause less postoperative sensitivity, which may be important in severely hypomineralized teeth. ${ }^{56}$

8. Self etching primer systems have also been reported to produce good ARI scores as compared to traditional acid-etch technique. ${ }^{46-47}$

Another alternative for orthodontic bracket adhesion is RMGIC, which posses the inert advantages of fluoride release ${ }^{24}$, ease of removal, lower Adhesive Remnant Index (ARI) scores, and a lower risk of damaging enamel surface, following orthodontic bracket removal. $27,28,30$ 
Interestingly, the combination of self-etching primer system with RMGIC was found (invitro) to enhance Shear Bond Strength of orthodontic brackets to normal bovine enamel.57 Furthermore, few clinical results indicated comparable failure rate between a composite resin adhesive when compared to Fuji Ortho LC in normal enamel.30,58However, to date, the effect of RMGIC bonding to hypomineralized enamel was not investigated.

\section{Clinical recommendation (see table):}

The severity of the hypomineralized enamel lesion is clinically evaluated by assessing surface enamel smoothness, hardness and color. Yellow-brown defects have a propensity to be deeper and more porous, and therefore may necessitate more cautious handling than white and white-creamy defects. 3,4

In cases of large yellow-brown opacities that cause an esthetic problem aggressive removal of all defective enamel, and a composite resin restoration, may be considered prior to bracket adhesion.5,22 If the clinician wishes to refrain from aggressive reduction of enamel, pretreatment with $5 \%$ sodium hypochlorite $(\mathrm{NaOCl})$ to remove protein encasing the hydroxylapatite is suggested, $56,59-62$ followed by a SEPBS.

In cases of white-creamy or creamy-yellow opacities that are covered with hard surface enamel (Fig. 3), definitive esthetic restoration of the defect may be postponed (if at all necessary) until the orthodontic treatment is finished. The recommended adhesive system is a SEPBS with a conventional composite resin-based adhesive. Alternatively, enamel pretreatment with SEPBS in combination with a RMGIC (Fuji Ortho LC (GC), may be considered.

Ceramic brackets reportedly cause more enamel loss and fracture at debonding than metal brackets, 42,43 and are not recommended for adhesion to hypomineralized enamel.

The removal of the residual adhesive can be accomplished via debonding pliers, and the enamel clean-up should be finished with a slow-speed tungsten carbide bur with water spray. 48

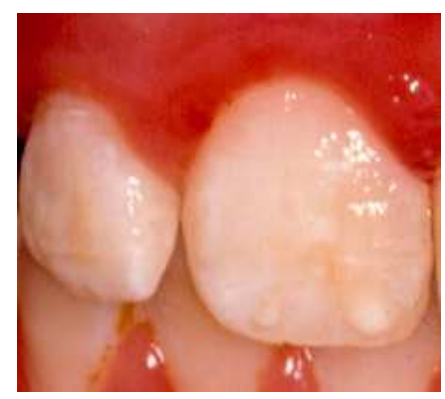

Fig. 3. Intraoral view of a 12-year-old girl with a low-severity demarcated opacities.

\section{Discussion}

Evidence-based recommendations on orthodontic adhesion to hypomineralized enamel do not exist in the dental literature. This may reflect the paucity of research investigating the adhesion of different bonding materials to hypomineralized enamel in general.19,59,61 The few articles published on specialized topic of adhesion of resin materials to hypomineralized enamel lack standardizations of bonding and adhesive systems used, differ in storage media, testing apparatus, specimen preparation, bonded surface area (fissures, ground cut or uncut enamel surface), and the severity of enamel defects. ${ }^{19}$ This 
precludes the authors of reviewing the subject in accordance with the Cochrane review system which emphasize reference containing clinically randomized controlled studies. Moreover, the conclusions drawn from investigating the adhesion of different adhesive systems to normal enamel may be inheritably tricky since the adhesion to hypomineralized enamel may posse's different charecteristics. ${ }^{19}$

\begin{tabular}{|c|}
\hline Preliminary dental treatment prior to fixed orthodontic appliance adhesion \\
\hline A. early diagnosis and risk assessment. \\
\hline B. Informed consent from the guardians/ patient \\
\hline $\begin{array}{l}\text { C. prevention of dental caries and post-eruption breakdown, enhance remineralization } \\
\text { and desensitization and maintenance Frequent recall appointments. }\end{array}$ \\
\hline $\begin{array}{l}\text { Active follow up and observation involving: oral hygiene instructions, dietary } \\
\text { consultation, application of Casein phosphopeptide-amorphous calcium phosphate (CPP- } \\
\text { ACP), and topical or systemic home and/or office fluoride regimen as indicated. }\end{array}$ \\
\hline $\begin{array}{l}\text { D. Considering long term prognosis of affected teeth and, if found necessary decide upon } \\
\text { extractions or restoration. }\end{array}$ \\
\hline 2. Modifications necessary for adhesion to hypomineralized enamel: \\
\hline A Prophylaxis with rubber cup and a paste containing up to $13,500 P P M$ Fluoride \\
\hline $\begin{array}{l}\text { B. Metal brackets or ceramic brackets with metal channel that debond like metal brackets } \\
\text { are recommended. }\end{array}$ \\
\hline $\begin{array}{l}\text { C. The adhesive system preferred for adhesion of orthodontic brackets to } \\
\text { hypomineralized teeth is dependent upon the lesion hardness and color: }\end{array}$ \\
\hline Large yellow-brown opacities: \\
\hline Option A) removal of all defective enamel, prior to a composite resin restoration. \\
\hline $\begin{array}{l}\text { Option B) pre-treatment with 5\% sodium hypochloride followed by a self etching primer- } \\
\text { bonding system. }\end{array}$ \\
\hline White-creamy or creamy-yellow opacities: \\
\hline $\begin{array}{l}\text { Option A) self etching system and adhesion of the orthodontic bracket with a } \\
\text { conventional composite resin based adhesive. }\end{array}$ \\
\hline $\begin{array}{l}\text { Option B) enamel pretreatment with self etching primer may be considered in } \\
\text { combination with a RMGIC (Fuji Ortho LC (GC). }\end{array}$ \\
\hline D. Debonding of brackets with pliers followed with residual adhesive removal \\
\hline by slow-speed tungsten carbide bur. \\
\hline
\end{tabular}

Table 1. Orthodontic management of enamel hypomineralization

Until more investigations are performed, several of our recommendations are at best educated assumptions.

The use of self-etching bonding systems may seem to yield more promising results. Nevertheless, few drawbacks should be stated:

1. They may not posses the same capacity as phosphoric acid to effectively etch uncut or unprepared enamel as is the case with orthodontic brackets adhesion to enamel. ${ }^{24-28,62}$

2. Auto-cure orthodontic resins (e.g., Concise, etc.) do not work well with the self-etch systems because the primer's acidity has been shown to interfere with the resins' polymerization. ${ }^{64}$ 
3. Some of those Self etching primers (e.g. Protect bond) may not work well with common LED curing light that do not cover the range of 400-515nm.

The clinician should be aware of these flaws when working with self-etching primers.

Yet, as frequently encountered in clinical situations, decision making on the management of situations as described in this text is necessary. We strongly believe that proper diagnosis and preventive management may assist the pediatric dentist as well as the orthodontist challenged by a patient with hypomineralized teeth.

Many questions are still left open and some answers to be wished for. Examples of still unanswered questions are: how does sodium hypochlorite conditioning of hypomineralized enamel affect the adhesion of RMGIC and resin adhesives, and how do the self-etching systems behave with those materials? Hopefully the uncertainties high lightened above enhance more research in this subject.

\section{References}

[1] Commission on Oral Health Research and Epidemiology] A review of the developmental defects of enamel index (DDE Index)] Commission on Oral Health Research and Epidemiology] Report of an FDI Working Group] Int Dent J, 1992; 42:411-426.

[2] Weerheijm KL, Jalevik B, Alaluusua S] Molar-incisor hypomineralization] Caries Res $2001 ; 35: 390-391$.

[3] Jalevik B, Odelius H, wolfram D et al] Secondary ion mass spectrometry and X-ray microanalysis of hypomineralized enamel in human permanent first molars] Arch Oral Biol 2000; 46:239-247.

[4] Suckling GW, Nelson DG, Patel MJ] Macroscopic and scanning electron microscopic appearance and hardness values of developmental defects in human of permanent teeth] Adv Dent Res 1989; 3:219-233]

[5] William V, Messer LB, Burrow MF] Molar incisor hypomineralization: review and recommendation for clinical management] Pediatr Dent 2006; 28:224-232.

[6] Ellwood RP, O'Mullane DM] Association between dental enamel opacities and dental caries in a north Wales population] Caries Res 1994; 28: 383-387.

[7] Leppaniemi A, Lukinmaa P-L, Alaluusua S] Nonfluoride hypomineralizations in the first molars and their impact on the treatment need] Caries Res 2001; 35: 36-40.

[8] Curzon MEJ, Spector PC] Enamel mottling in high strontium area of the USA] Community Dent Oral Epidem 1977; 5: 243-247.

[9] Borum MK, Andreasen JO] Sequelae of trauma to primary maxillary incisors] I] Complications in the primary dentition] Endod Dent Traumatol] 1998; 14: 31-44.

[10] Jarvinen S] Incisal overjet and traumatic injuries to upper permanent incisors] A retrospective study] Acta Odontol Scand 1978; 36:359-362.

[11] Odoi R, Croucher R, Wong F, Marcenes W] The relationship between problem behavior and traumatic dental injury amongst children aged 7-15 years old] Community Dent Oral Epidemiol] 2002; 30:392-396.

[12] Jalevik B, Klingberg G] Dental treatment, dental fear and behavior management problems in children with severe enamel hypomineralization in permanent first molars] Int J Ped Dent 2002; 12: 24-32.

[13] Jalevik B, Noren JG] Enamel hypomineralization of permanent first molars: a morphological study and survey of possible etiological factors] Int J Ped Dent 2000; 10:278-289. 
[14] American Academy of Pediatric Dentistry Council on Clinical Affairs: Use of a cariesrisk assessment tool (CAT) for infants, children, and adolescents] Pediatr Dent 2007-2008:29 (7 Reference Manual):29-33.

[15] Adair SM] Evidence-based use of fluoride in contemporary pediatric dental practice] Pediatr Dent 2006; 28:133-142.

[16] Giniger M, MacDonald J, Ziemba S, et al] The clinical performance of professionally dispensed bleaching gel with added amorphous calcium phosphate] JADA 2005; 136: 383-392.

[17] Iijima Y, Cai F, Shen P, et al] Acid resistance of enamel subsurface lesions remineralized by a sugar-free chewing gum containing casein phosphopeptide-amorphous calcium phosphate] Caries Res 2004; 38: 551-556.

[18] Kilpatrick N, Mahoney EK] Dental erosion: Part 2] The management of dental erosion] N Z Dent J 2004; 100:42-47.

[19] William V, Burrow MF, Palamara JEA, Messer LB] Microshear bond strength of resin composite to teeth affected by Molar hypomineralization using 2 adhesive systems] Pediatr Dent 2006; 28:233-241.

[20] Fayle SA] Molar-incisor hypomineralization: restorative management] European J Pediatr Dent 2003; 121-126.

[21] Penchas J, Peretz B, Becker A] The dilemma of treating severely decayed first permanent molars in children: To restore or to extract] ASDC J Dent Child 1994; 61:199-205.

[22] Zagdwon AM, Fayle SA, Pollard MA] A prospective clinical trial comparing metal crowns and cast restorations for defective first permanent molars] Eur J Paediatr Dent 2003; 4:138-142.

[23] Reddy L, Marker VA, Ellis E 3rd] Bond strength for orthodontic brackets contaminated by blood, composite versus resin-modified glass ionomer cements] J Oral Maxillofac Surg] 2003; 61(2): 206-213.

[24] Bishara SE, Gordan VV, Von Wald Let al] Shear bond strength of composite, glass ionomer, and acidic adhesive systems] Am J Orthod Dentofacial Orthop.1999; 115(1): 24-28.

[25] Buyukyilmaz T, Usumez S, Karaman AI] Effect of self-etching primers on bond strength-are the reliable?] Angle Orthod 2003; 73(1): 64-70.

[26] Grubisa HS, Heo G, Raboud D et al] An evaluation and comparision of orthodontic bracket bond strength achieved with self etching primer] Am J Orthod Dentofacial Orthop.2004; 126(2): 213-219.

[27] Bishara SE, Oonsombat C, Soliman MM et al] Comparison of bonding time and shear bond strength between a conventional and a new integrated bonding system] Angle Orthod] 2005; 75(2): 237-242.

[28] Aljubouri YD, Millett DT, Gilmour WH] Six and 12 months evaluation of a self-etching primer versus two-stage etch and prime for orthodontic bonding: a randomized clinical trial] Eur J Orthod 2004; 26(6):565-571.

[29] Corry A, Millett DT, Creanor SL et al] Effect of fluoride exposure on cariostatic potential of orthodontic bonding agents: an in vitro evaluation] J Orthod 2003; 30(4): 298-299.

[30] Hegarty DJ, Macfarlane TV] In vivo bracket retention comparision of a resin-modified glass ionomer cement and a resin based bracket adhesive system after a year] Am J Orthod Dentofacial Orthop.2002; 121(5): 496-501. 
[31] Wilson RM, Donly KJ] Demineralization around orthodontic brackets bonded with a modified glass ionomer cement and fluoride-releasing resin composite] Pediatr Dent 2001; 23(3): 255-259.

[32] Pascotto RC, Navarro MF, Capelozza Filho L et al] In vivo effect of a resin-modified glass ionomer cement on enamel demineralization around orthodontic brackets] Am J Orthod Dentofacial Orthop.2004;125(1): 36-41.

[33] Pus MD, Way DC] Enamel loss due to orthodontic bonding with filled and unfilled resin using various clean-up techniques] Am J Orthod 1980; 77:269-283.

[34] Thompson RE, Way DC] Enamel loss due to prophylaxis and multiple bonding/debonding oforthodontic brackets] Am J Orthod 1981; 79:282-295.

[35] Barry GRP] A clinical investigation of the effect of omission of pumice prophylaxis on band and bond failure] Br J Orthod 1995; 22:245-248.

[36] Ireland AJ, Sherriff M: The effect of pumicing on the in vivo use of a resin modified glass poly (alkenoate) cement and a conventional no-mix composite for bonding orthodontic brackets] 2002; 29: 217-220.

[37] Ireland AJ, Knight H, Sherriff M] An in vivo investigation into bond failure rates with a new self-etching primer system] Am J Orthod Dentofacial Orthop 2003; 124:323326.

[38] Damon PL, Bishara SE, Olsen ME et al] Effects of fluoride application on shear bond strength of orthodontic brackets] Angle Orthod] 1996; 66(1): 61-64.

[39] Ng'ang'a PM, Ogaard B, Cruz R et al] Tensile strength of orthodontic brackets bonded directly to fluorotic and nonfluorotic teeth: an in vitro comparative study] Am J Orthod Dentofacial Orthop.1992; 102(3): 244-250

[40] Kimura T, Dunn WJ, Taloumis LJ] Effect of fluoride varnish on the in vitro bond strength of orthodontic brackets using a self-etching primer system] Am J Orthod Dentofacial Orthop.2004; 125(3): 351-356.

[41] Meng CL, Li CH, Wang WN] Bond strength with APF applied after acid etching] Am J Orthod Dentofacial Orthop.1998; 114(5): 510-513.

[42] Joseph VP, Rossouw PE] The shear bond strengths of stainless steel orthodontic brackets bonded to teeth with orthodontic composite resin and various fissure sealants] Am J Orthod Dentofacial Orthop.1990; 98: 66-71.

[43] Jeroudi MT] Enamel fracture caused by ceramic brackets] Am J Orthod Dentofacial Orthop.1991; 99: 97-99.

[44] van Waes H, Matter T, Krejci I] Three-dimensional measurement of enamel loss caused by bonding and debonding of orthodontic brackets] Am J Orthod Dentofacial Orthop.1997; 112: 666-669.

[45] Tufekci E, Merrill TE, Pintado MR, Beyer JP, Brantley WA: Enamel loss associated with orthodontic adhesive removal on teeth with white spot lesions: An invitro study] Am J Orthod Dentofacial Orthop 2004; 125: 733-740]

[46] Vicente A, Bravo LA, Romero M] Self-etching primer and a non-rinse conditioner versus phosphoric acid: alternative methods for bonding brackets] Eur J Orthod 2006; 28:173-178.

[47] Vicente A, Bravo LA, Romero M, Ortiz AJ, Canteras M] Shear bond strength of orthodontic brackets bonded with self-etching primers] Am J Dent 2005; 18:256-260. 
[48] Hosein I, Sherriff M, Ireland AJ] Enamel loss during bonding, debonding, and clean-up with use of a self-etching primer] Am J Orthod Dentofacial Orthop 2004; 126:717724.

[49] Valente RM, De Rijk WG, Drummond JL et al] Etching conditions for resin-modified glass ionomer cement for orthodontic brackets] Am J Orthod Dentofacial Orthop.2002; 121;(25): 516-520.

[50] Cacciafesta V, Sfondrini MF, De Angelis et al] Effect of water and saliva contamination on shear bond strength of brackets bonded with conventional, hydrophilic and selfetching primers] Am J Orthod Dentofacial Orthop.2003; 123(4): 633-640.

[51] Cacciafesta V, Sfondrini MF, Scrbante A et al] Effect of blood contamination on shear bond strength of brackets bonded with a self-etching primer combined with a resinmodified glass ionomer] Am J Orthod Dentofacial Orthop.2004; 126(6): 703-708.

[52] Brandt PD Arhun N, Arman A, Sesen C, Karabulut E, Korkmaz Y, Gokalp S] Shear bond strength of orthodontic brackets with 3 self-etch adhesives] Am J Orthod Dentofacial Orthop.2006; 129: 547-550.

[53] Arhun N, Arman A, Sesen C, et al] Shear bond strength of orthodontic brackets with 3 self-etch adhesives] Am J Orthod Dentofacial Orthop.2006; 129: 547-550.

[54] Eminkahyagil N, Korkmaz Y, Gokalp S, et al] Shear bond strength of orthodontic brackets with newly developed self-etch adhesive] Angle Orthod 2005; 75: 843-848.

[55] Korbmacher H, Huck L, Adam T, Kahl-Nieke B] Evaluation of an antimicrobial and fluoride-releasing self-etching primer on the shear bond strength of orthodontic brackets] Eur Orthod 2006;

[56] Suda R, Andoh Y, Shionome M, et al] Clinical evaluation of the sedative effect of HEMA solution on the hypersensitivity of dentin] Dent Mater J 1990;9: 163-166.

[57] Cacciafesta V, Sfondrini MF, Baluga L et al] Use of a self-etching primer in combination with a resin-modified glass ionomer: effect of water and saliva contamination on shear bond strength] Am J Orthod Dentofacial Orthop.2003; 124(4): 420-426.

[58] Summers A, Kao E, Gilmore J et al] Comparision of bond strength between a conventional resin adhesive and a resin- modified glass ionomer adhesive: an in vitro and in vivo study] Am J Orthod Dentofacial Orthop.2004; 126(2): 200-206.

[59] Venezie RD, Vadiakas G, Christensen JR et.al] Enamel pretreatment with sodium hypochlorite to enhance bonding in hypocalcified amelogenesis imperfecta: case report and SEM analysis] Pediatr Dent 1994; 16: 433-436. 


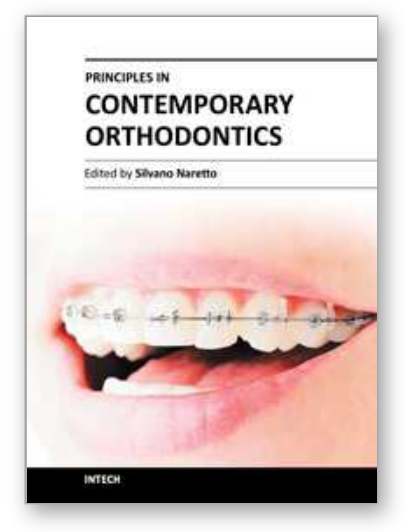

\author{
Principles in Contemporary Orthodontics \\ Edited by Dr. Silvano Naretto
}

ISBN 978-953-307-687-4

Hard cover, 584 pages

Publisher InTech

Published online 25, November, 2011

Published in print edition November, 2011

Orthodontics is a fast developing science as well as the field of medicine in general. The attempt of this book is to propose new possibilities and new ways of thinking about Orthodontics beside the ones presented in established and outstanding publications available elsewhere. Some of the presented chapters transmit basic information, other clinical experiences and further offer even a window to the future. In the hands of the reader this book could provide an useful tool for the exploration of the application of information, knowledge and belief to some orthodontic topics and questions.

\title{
How to reference
}

In order to correctly reference this scholarly work, feel free to copy and paste the following:

Shabtai Sapir (2011). Considerations in Orthodontic Bracket Adhesion to Hypomineralized Enamel, Principles in Contemporary Orthodontics, Dr. Silvano Naretto (Ed.), ISBN: 978-953-307-687-4, InTech, Available from: http://www.intechopen.com/books/principles-in-contemporary-orthodontics/considerations-in-orthodonticbracket-adhesion-to-hypomineralized-enamel

\section{INTECH}

open science | open minds

\section{InTech Europe}

University Campus STeP Ri

Slavka Krautzeka 83/A

51000 Rijeka, Croatia

Phone: +385 (51) 770447

Fax: +385 (51) 686166

www.intechopen.com

\section{InTech China}

Unit 405, Office Block, Hotel Equatorial Shanghai

No.65, Yan An Road (West), Shanghai, 200040, China

中国上海市延安西路65号上海国际贵都大饭店办公楼405单元

Phone: +86-21-62489820

Fax: +86-21-62489821 
(C) 2011 The Author(s). Licensee IntechOpen. This is an open access article distributed under the terms of the Creative Commons Attribution 3.0 License, which permits unrestricted use, distribution, and reproduction in any medium, provided the original work is properly cited. 